\title{
Custo Aluno Qualidade inicial, $10 \%$ do PIB e uma nova fonte de receita: novas perspectivas para o financiamento da Educação Básica?
}

\author{
The initial cost pupil quality, $10 \%$ of PIB and a new source of revenue: new \\ perspectives for the financing of basic education? \\ Calidad del estudiante coste inicial, el 10\% del PIB y una nueva fuente de \\ ingresos: ¿nuevas perspectivas para la financiación de la educación básica?
}

CACILDA RODRIGUES CAVALCANTI

\begin{abstract}
Resumo: $\mathrm{O}$ artigo apresenta as proposições, iniciativas e debates que tomaram corpo na década de 2000 no campo do financiamento da Educação Básica no Brasil. Combinando pesquisa documental e estatística descritiva, analisa os limites e as perspectivas desses novos arranjos para o alcance de um padrão de qualidade, em resposta ao cumprimento do direito à educação. Argumenta em favor da implantação do Custo Aluno Qualidade inicial e de uma maior participação da União para o alcance de um padrão mínimo de Qualidade.
\end{abstract}

Palavras-chave: Educação Básica. Financiamento. Qualidade.

\begin{abstract}
The paper presents the proposals, initiatives and debates that took shape in the decade of 2000 in the field of basic education financing in Brazil. Combining documentary research and descriptive statistics, it analyses the limits and perspectives of these new arrangements to achieve a standard of quality in response to the accomplishment of the right to education. This paper argues for the implementation of the Initial Cost Pupil Quality and of a greater participation of the Union to reach a minimum quality standard.
\end{abstract}

Keywords: Basic education; funding; quality.

Resumen: El artículo presenta las propuestas, iniciativas y debates que se concretaron en la década de 2000 en el ámbito de la financiación de educación básica en Brasil. Combinando la investigación documental y estadística descriptiva, analiza los límites y las perspectivas de estas nuevas disposiciones para lograr un estándar de calidad, en respuesta al cumplimiento del derecho a la educación. Argumenta a favor de la aplicación de la calidad inicial de costos del estudiante y una mayor participación de la Unión para alcanzar un estándar mínimo de calidad.

Palabras clave: Educación básica. Financiación. Calidad. 


\section{INTRODUÇÃO}

A Constituição Federal de 1988 incluiu, em seu Artigo 206, inciso VII, a "garantia de padrão de qualidade" (BRASIL, 1988, Art. 206) como um dos princípios a ser considerado na oferta do ensino. Esse dispositivo teve importantes implicações para o campo do financiamento da Educação Básica, trazendo à tona o debate acerca da definição de parâmetros para o investimento necessário à oferta e à manutenção da Educação Básica com qualidade.

Embora a CF/1988 tenha associado o direito à educação e a obrigatoriedade do Estado por sua garantia a um padrão de qualidade, a primeira década que se seguiu ainda foi marcada por iniciativas em torno da quantidade e, ainda assim, limitada à expansão da oferta do Ensino Fundamental, etapa determinada como a escolaridade obrigatória. Nesse contexto, o preceito da qualidade, quando esteve presente na agenda governamental, esteve fortemente vinculado à ideia de eficiência na gestão dos recursos, entendida como fazer mais com menos custos, ou seja, aumentar a oferta sem aumentar o gasto em educação. Consequentemente, questões como a definição do investimento necessário para a garantia da oferta de educação com padrões mínimos de qualidade não tiveram repercussão suficiente na agenda governamental.

No campo específico do financiamento da Educação Básica, o debate da qualidade assumiu maior repercussão a partir da aprovação da LDB n ${ }^{\circ}$ 9.394/1996, que, em seu Artigo $4^{\circ}$, deu maior especificidade ao que seria o padrão de qualidade.

O dever do Estado com educação escolar pública será efetivado mediante a garantia de:[...] IX - padrões mínimos de qualidade de ensino, definidos como a variedade e quantidade mínimas, por aluno, de insumos indispensáveis ao desenvolvimento do processo de ensino-aprendizagem. (BRASIL, 1996a, Art. $4^{\circ}$ ).

Além disso, no parágrafo $1^{\circ}$ do Artigo 75, a referida Lei estabeleceu um referencial sobre o qual deveria ser definida a fórmula de cálculo do custo-aluno na perspectiva do padrão mínimo de qualidade.

$\int 1^{\circ} \mathrm{A}$ ação a que se refere este Artigo obedecerá a fórmula de domínio público que inclua a capacidade de atendimento e a medida do esforço fiscal do respectivo Estado, do Distrito Federal ou do Município em favor da manutenção e do desenvolvimento do ensino. [...] $\int 2^{\circ}$ A capacidade de atendimento de cada governo será definida pela razão entre os recursos de uso constitucionalmente obrigatório na manutenção e desenvolvimento do ensino e o custo anual do aluno, relativo ao padrão mínimo de qualidade. (Idem, grifo nosso) 
Embora o texto da Lei $\mathrm{n}^{\circ}$ 9.394/1996, a LDB, tenha avançado na especificação do padrão mínimo de qualidade, circunscreveu esse padrão ao âmbito do Ensino Fundamental, em oposição à concepção de Educação Básica presente na mesma lei.

Quando da aprovação da Lei no 9.424/1996, que regulamentou o Fundo de Manutenção e Desenvolvimento do Ensino Fundamental e de Valorização do Magistério (Fundef), ficaram definidos, em seu Artigo 13, os critérios a serem observados no estabelecimento do padrão mínimo de qualidade, nos seguintes termos:

\footnotetext{
Para os ajustes progressivos de contribuições a valor que corresponda a um padrão de qualidade de ensino, definido nacionalmente e previsto no $\ 4^{\circ}$ do art. 60 Atos das Disposições Constitucionais Transitórias, serão considerados, observando o disposto no $₫ 2^{\circ}$ do art. $2^{\circ}$, os seguintes critérios: [...] I - estabelecimento do número mínimo e máximo de alunos em sala de aula; [...] II - capacitação permanente dos profissionais de educação; [...] III - jornada de trabalho que incorpore os momentos diferenciados das atividades docentes; [...] IV - complexidade de funcionamento; [...] V - localização e atendimento da clientela; [...] VI - busca do aumento do padrão de qualidade de ensino (BRASIL, 1996b, Art. 13).
}

Essa especificação forneceu bases para uma definição do investimento necessário para o alcance de um padrão de qualidade na Educação Básica, incluindo dimensões fundamentais da oferta educacional. No entanto, não foram tomadas iniciativas por parte do governo para a definição de um valor/aluno ancorado em insumos e condições necessários ao alcance de um padrão de qualidade em todo o território brasileiro.

No contexto de aprovação do Fundo de Manutenção e Desenvolvimento da Educação Básica e de Valorização dos Profissionais da Educação (Fundeb) e do novo Plano Nacional de Educação, o debate acerca do Custo Aluno Qualidade ganhou espaço, resultando em algumas iniciativas nessa direção, sendo a meta de investimento de $10 \%$ do PIB e uma nova fonte de recursos oriundos dos royalties do petróleo concebidas como potencializadoras da expansão dos investimentos em educação para o alcance de um padrão mínimo de qualidade.

O presente estudo tem como foco a análise das perspectivas de alcance do Custo Aluno Qualidade a partir dos novos arranjos no financiamento da Educação Básica instituídos por meio do Fundeb, dos royalties do petróleo e da meta de alcance de 10\% do PIB. O artigo se inicia com um breve histórico da proposta de Custo Aluno Qualidade inicial (CAQi) para, em seguida, analisar as duas principais medidas em direção de seu alcance: a meta de investimento de 10\% do PIB e a receita dos royalties do petróleo. A análise procedida, com base em pesquisa documental e estatística descritiva, evidencia que as medidas ainda 
não apresentaram efeito na direção de alcance do CAQi e que os novos arranjos têm-se limitado à administração de um limite de recursos, não havendo aumento significativo destes desde 2010.

\title{
AS PROPOSIÇÕES DO CUSTO ALUNO-QUALIDADE INICIAL
}

No processo de aprovação Fundeb, por meio do movimento "Fundeb pra Valer!", liderado pela Campanha Nacional pelo Direito à Educação (CNDE), a referência ao padrão mínimo de qualidade, base para a definição de um Custo Aluno-Qualidade (CAQ), foi incorporada no texto da Emenda Constitucional 53/2006, que instituiu o Fundeb (CARREIRA; PINTO, 2007). Consequentemente, a Lei $n^{\circ} 11.494$ de 2007, que regulamentou o Fundeb, no Artigo 30, ao definir as obrigações do Ministério da Educação, incluiu no inciso IV, a "realização de estudos técnicos com vistas à definição do valor referencial anual por aluno que assegure padrão mínimo de qualidade do ensino" (p.14). E, em seu Artigo 38, assegurou a participação popular na definição do referido padrão. (BRASIL, 2007c). Contudo, não foram desenvolvidas ações efetivas na perspectiva da definição de um Custo Aluno-Qualidade ${ }^{1}$.

Diante da inércia do governo federal nessa direção, desde 2002, a CNDE havia estabelecido como uma de suas metas a construção de referenciais de Custo Aluno-Qualidade (CAQ), ação cujo objetivo final era a elaboração e o encaminhamento de um documento com propostas sobre o CAQ ao Executivo e ao Legislativo federais. Assim, a partir desse processo, buscou-se definir uma matriz referencial do Custo Aluno-Qualidade, com base no consenso de que

\begin{abstract}
Em um sistema de educação de massa, a qualidade do ensino está associada à qualidade dos processos de ensino e aprendizagem, o que, por sua vez, se relaciona à qualidade dos insumos utilizados. Em outras palavras, a ideia central é de que a garantia de insumos adequados seja condição necessária - ainda que não suficiente - para a qualidade do ensino. Embora concordemos que a definição de qualidade não deve passar apenas pela definição de insumos, do ponto de vista dos custos, que é o foco de nossa proposta, a garantia de infraestrutura e equipamentos adequados e de condições de trabalho satisfatórias é um componente imprescindível para a efetividade dos processos de ensino e aprendizagem. (CARREIRA; PINTO, 2007 p. 25)
\end{abstract}

A CNDE optou, politicamente, pela definição de um Custo AlunoQualidade inicial (CAQi) como estratégia de torná-la viável diante da situação

\footnotetext{
1 O MEC, por meio do INEP, desenvolveu um estudo sobre custo-aluno, cuja finalidade seria subsidiar as decisões nessa direção. O estudo foi publicado em 2005, mas não foram tomadas iniciativas concretas na perspectiva da instituição do Custo Aluno Qualidade. (ARAÚJO, 2013).
}

490 - RBPAE - v. 32, n. 2, p. 487 - 507 mai./ago. 2016 
vigente. A matriz do CAQi foi elaborada a partir do cruzamento de variáveis que relacionam "a qualidade oferecida nas etapas e nas modalidades com os insumos necessários, os desafios referentes aos recortes de equidade que impactam a educação e as dimensões fundamentais dos processos de ensino e aprendizagem" (Ibidem). Assim, foram definidas quatro categorias de insumos: I) insumos relacionados à estrutura e funcionamento da escola (construção e manutenção dos prédios e materiais básicos de conservação e equipamentos de apoio ao ensino); II) insumos relacionados às trabalhadoras e aos trabalhadores em educação (condições de trabalho, salários, plano de carreira, jornada de trabalho e formação inicial e continuada dos trabalhadores e das trabalhadoras em educação); III) insumos relacionados à gestão democrática (fomento à participação da comunidade escolar, trabalho em equipe, construção conjunta do projeto pedagógico, democratização da gestão da escola, entre outros); e IV) insumos relacionados ao acesso e à permanência na escola (material didático, transporte, alimentação, vestuário).

No cálculo do CAQi, quatro fatores foram considerados como os de maior impacto pelos autores: a) tamanho da escola/creche; b) jornada dos alunos e das alunas; c) a relação alunos/turma ou alunos/professor; d) os salários das/dos profissionais da educação. Assim, os autores definiram o CAQi para cada etapa e modalidade da Educação Básica, considerando, ainda, seus ciclos e diferenciando custos de implantação e manutenção, conforme sintetizados na tabela a seguir

Tabela 1 - Síntese de parâmetros e valores do CAQi

\begin{tabular}{|c|c|c|c|c|c|c|c|}
\hline \multirow{2}{*}{ Tipo de escola } & \multirow{2}{*}{ Creche } & \multirow{2}{*}{$\begin{array}{l}\text { Pré- } \\
\text { escola }\end{array}$} & \multicolumn{2}{|c|}{ Ensino Fundamental } & \multirow{2}{*}{$\begin{array}{l}\text { Ensino } \\
\text { Médio }\end{array}$} & \multicolumn{2}{|c|}{$\begin{array}{l}\text { Ens. Fundamental do } \\
\text { Campo }\end{array}$} \\
\hline & & & $\begin{array}{l}\text { Séries } \\
\text { Iniciais }\end{array}$ & $\begin{array}{l}\text { Séries } \\
\text { Finais }\end{array}$ & & $\begin{array}{l}\text { Séries } \\
\text { Iniciais }\end{array}$ & $\begin{array}{l}\text { Séries } \\
\text { Finais }\end{array}$ \\
\hline Tamanho médio (alunos) & 120 & 264 & 400 & 600 & 900 & 60 & 100 \\
\hline $\begin{array}{l}\text { Jornada diária dos alunos } \\
\text { (horas) }\end{array}$ & 10 & 5 & 5 & 5 & 5 & 5 & 5 \\
\hline Média de alunos por turma & 12 & 22 & 25 & 30 & 30 & 12 & 25 \\
\hline Pessoal+encargos (\%) & $79,3 \%$ & $74,3 \%$ & $73,5 \%$ & $73,3 \%$ & $74,3 \%$ & $74,9 \%$ & $74,2 \%$ \\
\hline Custo MDE (R\$) & 3.783 & 1.659 & 1.618 & 1.591 & 1.645 & 1.997 & 2.166 \\
\hline Custo total (R\$ em 2005) & 4.139 & 1.789 & 1.724 & 1.697 & 1.746 & 2.390 & 2.319 \\
\hline $\begin{array}{l}\text { Custo total (\% do PIB per } \\
\text { capita) }\end{array}$ & $39,3 \%$ & $17 \%$ & $16,4 \%$ & $16,1 \%$ & $16,6 \%$ & $22,7 \%$ & $22 \%$ \\
\hline $\begin{array}{c}\text { Diferenciação }\left(E F 1^{\mathrm{a}} \text { a } 4^{\mathrm{a}}\right. \\
\text { série }=1)\end{array}$ & 2,4 & 1,04 & 1 & 0,98 & 1,01 & 1,39 & 1,34 \\
\hline
\end{tabular}

Obs: Exclui gastos com alimentação.

EF: Ensino Fundamental; MDE: Manutenção e Desenvolvimento do Ensino.

Fonte: Carreira e Pinto (2007, p.111) 
A definição do CAQi levou em conta insumos e condições necessárias para o alcance de padrões de qualidade, considerando um aspecto essencial da realidade brasileira - a desigualdade existente entre as unidades da federação na oferta de ensino e nas condições financeiras disponíveis para o atendimento da demanda em quantidade e qualidade necessárias, o que se expressou em diferentes fatores de ponderação entre etapas, modalidades e a localização da oferta de ensino, baseados em critérios que consideram as diferenças de custo da oferta em cada situação específica. No contexto brasileiro, marcado por grande diversidade que resulta em diferentes características das redes de ensino, tanto no que se refere à quantidade quanto à qualidade, tais critérios têm grande significado para o alcance da equidade. Há estados e municípios que possuem mais desafios na oferta da educação com qualidade do que outros, dependendo das modalidades e de onde estão localizadas a oferta ou mesmo a demanda a ser atendida. Portanto, valor/aluno diferenciado e em patamar mais coerente com o custo da oferta em cada situação específica constitui um estímulo aos governos para a ampliação e melhoria da oferta de educação em áreas, modalidades ou segmentos nos quais a oferta ainda é limitada e precarizada diante da demanda, a exemplo da oferta de creches, ensino médio nas áreas rurais, educação indígena e educação em tempo integral.

Outro aspecto importante para o alcance da equidade é a diferenciação estabelecida entre os custos de implantação e os custos de manutenção de creches e escolas, pois, enquanto em algumas regiões do país os custos de implantação já não são tão imperativos, em outras, os custos de implantação ainda se impõem, em especial, quando se trata da Educação Infantil e do Ensino Médio.

O CAQi ganhou importante espaço nos debates ocorridos na Conferência Nacional de Educação (CONAE) realizada em 2010 em Brasília-DF, a qual o indicou como referência para o caminho a ser trilhado para que a Educação Básica pública alcance um padrão mínimo de qualidade.

Como alternativa ao atual desequilíbrio regional e à oferta de Educação Básica pública, o financiamento à educação deve tomar como referência, e em caráter de urgência, o mecanismo do custo aluno/a-qualidade (CAQ). Previsto no ordenamento jurídico brasileiro, o CAQ deve ser definido a partir do custo anual por estudante dos insumos educacionais necessários para que a Educação Básica pública adquira e se realize com base em um padrão mínimo de qualidade. (BRASIL, 2010a, p.104).

$\mathrm{Na}$ perspectiva de viabilizar o CAQ, a Conferência aprovou propostas de alterações importantes na atual estrutura de financiamento, entre as quais se destacam: a) garantir o aumento dos recursos da educação de 18\% para, no mínimo, $25 \%$ da União e de 25\% para, no mínimo, 30\% de estados, DF e municípios, não

492 - RBPAE - v. 32, n. 2, p. 487 - 507 mai./ago. 2016 
só da receita de impostos, mas se adicionando, de forma adequada, percentuais das taxas e contribuições sociais para investimento em manutenção e desenvolvimento do ensino público ${ }^{2}$ b) ampliar o investimento em educação pública em relação ao PIB, na proporção de, no mínimo, 1\% ao ano, de forma a atingir, no mínimo, 7\% do PIB até 2011 e, no mínimo, 10\% do PIB até 2014; c) definir e aperfeiçoar os mecanismos de acompanhamento, fiscalização e avaliação da sociedade, articulados entre os órgãos responsáveis (conselhos, Ministério Público, Tribunal de Contas), para que seja assegurado o cumprimento da aplicação dos percentuais mínimos na manutenção e desenvolvimento do ensino (MDE); d) extinguir o sistema de balizas que limitam os fatores de ponderação do fundo a uma escala de 0,7 a 1,3, como medida imprescindível para substituir a atual perspectiva do gasto-aluno(a)/ano ou custo-aluno(a)/ano existente no fundo, por uma política de custo-aluno/a-qualidade.

O movimento em torno do CAQi ecoou também no Conselho Nacional de Educação que, em 05 de maio de 2010, aprovou Parecer favorável à sua viabilização. O Parecer $\mathrm{CNE} / \mathrm{CEB} \mathrm{n}^{\circ}$ 08/2010 discorre sobre alguns graves problemas brasileiros referentes à qualidade da Educação Básica no Brasil e também acerca de algumas medidas tomadas pelo governo federal na direção de corrigi-los e, a partir disso, mostra que tal realidade e tais medidas não podem se efetivar com a atual matriz de financiamento da educação e argumenta em favor de um financiamento que considere o CAQi.

Nesse sentido, o presente Parecer identificou o Custo Aluno Qualidade inicial (CAQi), desenvolvido pela Campanha Nacional pelo Direito a Educação, como referência para a construção da matriz de Padrões Mínimos de Qualidade para a Educação Básica Publica no Brasil. (BRASIL, 2010b)

Assim, o CNE, por meio da Câmara de Educação Básica (CEB), aprovou o parecer, seguindo a perspectiva do CAQi elaborado pela Campanha Nacional pelo Direito à Educação, com valores atualizados, em função das mudanças introduzidas pelo Ensino Fundamental de 9 anos, que levaram a alterações no número médio de alunos em creche, pré-escola e anos iniciais do Ensino Fundamental.

O Parecer CNE/CEB no 08/2010 foi importante passo na perspectiva de mobilização do executivo e do legislativo para a instituição do CAQi, porém, passados seis anos de sua aprovação, ainda aguarda pela homologação do ministro da educação, fato que traz implicitamente indícios da resistência do governo

2 Ressalte-se, nesse aspecto, que a proposta de vinculação de percentuais das taxas e contribuições incorre em um erro quanto a tal possibilidade, uma vez que as taxas, conforme a CF/1988, estão vinculadas à prestação de serviços aos seus contribuintes e as contribuições aos fins específicos para os quais foram criadas. 
federal quanto a tal proposição. Em que pese a não homologação do Parecer pelo ministro, as iniciativas aqui relatadas na direção do CAQi trouxeram importantes debates para a agenda do financiamento da educação pública, entre eles o da vinculação de percentuais de seu financiamento da ao PIB em um patamar de $10 \%$, que tomou lugar nos debates do processo de tramitação do PNE 20142024.

\section{INVESTIMENTO DE 10\% DO PIB, ROYALTIES DO PETRÓLEO E A PERSPECTIVA DE IMPLEMENTAÇÃO DO CAQI}

A proposição e os movimentos em torno do Custo Aluno Qualidade inicial conduziram a medidas importantes no Fundeb, tais como maior diversificação de fatores de ponderação conforme etapas e modalidades bem como outras especificidades da Educação Básica e a definição de um percentual mínimo da complementação da União. Porém, os valores/aluno praticados ainda se mostram muito aquém de um Custo Aluno Qualidade.

Nessa direção, movimentos e organizações sociais em defesa da educação pública com qualidade fizeram, nas CONAEs e no processo de aprovação do novo PNE (2011-2020), ampla mobilização em torno da ampliação do investimento em educação para o alcance do CAQi.

No Projeto de Lei no 8.035/2010, visando à aprovação do novo PNE, estava contida a proposta de aplicação de 7\% do PIB em educação, ao longo da década: "Ampliar progressivamente o investimento público em educação até atingir, no mínimo, o patamar de sete por cento do produto interno bruto do país." (BRASIL, 2010c, meta 20).

Em documento, (BRASIL, 2010d), o governo federal apresentou estudo que mostrava um investimento na ordem 5\% do PIB até o ano de 2009. No cálculo, segundo o documento, não foram incluídos gastos com aposentadorias e pensões, bolsas de estudo, financiamento estudantil, juros, amortizações e encargos da dívida da área educacional. Sendo assim, o documento permite entender que foram incluídas as transferências para entidades privadas filantrópicas e comunitárias, via Fundeb e programas do FNDE. Assim, a meta de 7\% foi calculada com base nesse percentual de 5\% em 2009, aplicando-se uma taxa de crescimento médio anual de $0,2 \%$, conforme movimento que vinha sendo feito nos últimos cinco anos. Portanto, não incorporou esforços no sentido de superação dessa taxa de crescimento médio.

Tal proposta foi alvo de intensos debates e estudos por parte da sociedade civil, que buscou mostrar não ser tal percentual suficiente para garantir a educação de qualidade ensejada pelo plano, uma vez que não incorporava novas fontes

494 - RBPAE - v. 32, n. 2, p. 487 - 507 mai./ago. 2016 
e maior aporte de recursos em relação ao que já vinha sendo realizado. Surge assim, em setembro de 2011, a "campanha 10\% do PIB na educação pública já”, assinada por um conjunto de entidades sindicais e outras organizações não governamentais, ancorando-se na proposição do CAQi.

A partir de então, trava-se uma disputa entre a proposta do governo (que oscilava entre $7 \%$ e $8 \%$ ) e a proposta da campanha, de $10 \%$. Nesse processo, a disputa envolve não somente o percentual do PIB a ser vinculado, mas também a concepção de investimento em educação pública versus a concepção de investimento público em educação. Para os defensores dos 10\%, esse percentual deveria incluir apenas os gastos em educação pública, excluindo-se, portanto, os recursos investidos nas instituições privadas de ensino, bem como os gastos com aposentados e pensionistas.

Em meio ao debate na Câmara Federal, o relator do projeto apresentou uma proposta intermediária de $8,3 \%$ do PIB, mas alterando o texto, de forma que tal percentual abrangeria não somente os investimentos nas redes públicas, mas também os investimentos públicos na rede privada. Considerando que os percentuais atuais investidos no setor privado (somando-se transferências do Fundeb, dos programas do FNDE, Prouni e FIES) giram em torno de 1,5\% (ARAÚJO, 2013), tal proposição se apresentou mais como uma manobra do que uma proposta de expansão dos percentuais para além do que já havia sido proposto pelo governo federal. Porém, esta não foi aceita pela maioria da Comissão Especial do PNE na Câmara Federal, que aprovou um investimento equivalente a 10\% do PIB para a educação pública e, assim, seguiu para o Senado Federal.

No Senado Federal, o debate acerca do investimento em proporção ao PIB voltou à tona e novas propostas de redação à meta 20 foram apresentadas, resultando na exclusão do adjetivo "pública" que assegurava, para efeito do cálculo dos 10\% do PIB, apenas os investimentos em "educação pública”, prevalecendo a generalização no texto.

Em março de 2014, em resposta a requerimento do Senado, o MEC nota técnica (BRASIL, 2014) no qual apresenta dois resultados sobre o percentual do PIB investido no período de 2000 a 2012, com base em estudos do INEP. A nota diferencia investimento público total de investimento público direto. Assim, o primeiro é concebido como sendo a "soma de recursos investidos pelo setor público em educação, tanto pública quanto privada" e, por sua vez, o investimento público direto como sendo a "soma de recursos investidos pelo setor público em educação pública".

As duas tabelas a seguir mostram os resultados do estudo do INEP. (BRASIL, 2014). 
Tabela 2 - Estimativa do percentual de Investimento Público Total em Educação em relação ao PIB, por esfera de governo - Brasil 2000 - 2012

\begin{tabular}{|c|c|c|c|c|}
\hline \multirow{2}{*}{ ANO } & \multicolumn{3}{|c|}{ Percentual de Investimento Público Total em relação ao PIB } \\
\cline { 2 - 5 } & \multirow{2}{*}{$\begin{array}{c}\text { Todos os níveis de } \\
\text { ensino }\end{array}$} & \multicolumn{3}{|c|}{ Esferas de Governo } \\
\cline { 3 - 5 } & 4,7 & 0,9 & 2,0 & Mederal \\
\hline 2000 & 4,8 & 0,9 & 2,0 & 1,8 \\
\hline 2001 & 4,8 & 0,9 & 2,1 & 1,8 \\
\hline 2002 & 4,6 & 0,9 & 1,9 & 1,8 \\
\hline 2003 & 4,5 & 0,8 & 1,8 & 1,8 \\
\hline 2004 & 4,5 & 0,8 & 1,8 & 1,9 \\
\hline 2005 & 5,0 & 0,9 & 2,1 & 2,0 \\
\hline 2006 & 5,2 & 1,0 & 2,1 & 2,0 \\
\hline 2007 & 5,4 & 1,0 & 2,3 & 2,1 \\
\hline 2008 & 5,7 & 1,2 & 2,3 & 2,2 \\
\hline 2009 & 5,8 & 1,2 & 2,3 & 2,3 \\
\hline 2010 & 6,1 & 1,3 & 2,5 & 2,3 \\
\hline 2011 & 6,4 & 1,3 & 2,5 & 2,6 \\
\hline 2012 & & & & \\
\hline
\end{tabular}

Fonte: Brasil, 2014.

Os dados da Tabela 2 mostram que de 2010 a 2012, o Investimento Público Total em educação cresceu apenas 0,6 pontos percentuais, ou seja, a uma razão de 0,3 ao ano, portanto 0,1 a mais que a taxa prevista no estudo do MEC, que acompanhou a proposta inicial do novo PNE. Assim, ainda considerando todos os gastos do setor público em educação (pública e privada), conforme aprovado no PNE 2014-2024, mantendo-se essa mesma taxa de crescimento, a meta de 10\% não seria alcançada; até o fim da década, chegaria a apenas 8,8.

Considerando o Investimento Público Direto, ou seja, apenas os recursos investidos pelo setor público em educação pública, essa distância é ainda maior. Os dados da Tabela 3 mostram que de 2010 a 2012, o Investimento Público Direto em educação cresceu apenas 0,4 pontos percentuais - uma taxa anual de 0,2. Portanto, mantendo-se essa mesma taxa de crescimento, até o fim da década, alcançar-se-iam apenas $7 \%$ do PIB, em conformidade com o previsto no estudo do MEC, que acompanhou a proposta inicial do PNE. Portanto, tomando-se a concepção de Investimento Público Direto, o alcance da meta de 10\% do PIB até o fim da década, exigiria esforços mais intensos por parte dos entes federados, principalmente, da União. 
Tabela 3 - Estimativa do percentual de Investimento Público Direto em Educação em relação ao PIB, por esfera de governo - Brasil 2000 - 2012.

\begin{tabular}{|c|c|c|c|c|}
\hline \multirow{2}{*}{ ANO } & \multicolumn{4}{|c|}{ Percentual de Investimento Público Total em relação ao PIB } \\
\cline { 2 - 5 } & \multirow{2}{*}{$\begin{array}{c}\text { Todos os níveis de } \\
\text { ensino }\end{array}$} & Federal & Estadual & Municipal \\
\cline { 3 - 5 } & 3,9 & 0,7 & 1,7 & 1,5 \\
\hline 2000 & 4,0 & 0,8 & 1,7 & 1,6 \\
\hline 2001 & 4,1 & 0,7 & 1,8 & 1,6 \\
\hline 2002 & 3,9 & 0,7 & 1,6 & 1,6 \\
\hline 2003 & 3,9 & 0,6 & 1,6 & 1,7 \\
\hline 2004 & 3,9 & 0,7 & 1,6 & 1,7 \\
\hline 2005 & 4,3 & 0,7 & 1,8 & 1,7 \\
\hline 2006 & 4,5 & 0,8 & 1,9 & 1,8 \\
\hline 2007 & 4,7 & 0,8 & 2,0 & 1,9 \\
\hline 2008 & 5,0 & 1,0 & 2,0 & 1,9 \\
\hline 2009 & 5,1 & 1,0 & 2,0 & 2,0 \\
\hline 2010 & 5,3 & 1,1 & 2,1 & 2,0 \\
\hline 2011 & 5,5 & 1,0 & 2,2 & 2,3 \\
\hline 2012 & & & & \\
\hline
\end{tabular}

Fonte: Brasil, 2014.

Assim, é compreensível a insistência do governo em manter percentuais entre 7 e 8,3\% do PIB e, sendo aprovados os 10\%, manter a inclusão dos investimentos feitos na iniciativa privada, o que aumenta a possibilidade de alcance de percentuais mais próximos da meta estabelecida.

De volta à Câmara Federal, o PNE foi aprovado, em 03 de junho de 2014, mantendo-se a meta de investimento de 10\% do PIB e a mudança na redação, pequena mas de grande significado: ao invés de ampliar o investimento público em educação pública, o texto aprovado foi ampliar o investimento público em educação. Com essa sutil exclusão do adjetivo pública, abre-se a possibilidade de incluir os recursos repassados para a iniciativa privada no cômputo dos gastos em educação. Assim, concordando com Araújo (2013), o percentual de investimento público na educação pública não será de $10 \%$ do PIB, mas deve ficar em torno de 8,5\% do PIB, caso não cresça o percentual atual de destinação de recursos públicos para a área privada.

A aprovação da meta do PNE 2014-2024 de vinculação dos investimentos em educação a um patamar de 10\% do PIB estabeleceu o desafio de aumentar os recursos disponíveis para a educação. Nessa perspectiva e no contexto de intensos debates e demandas da sociedade civil, foi aprovada em 9 de setembro de 2013, a Lei $n^{\circ} 12.858$, que obriga a União, os Estados e os Municípios a aplicarem 
$75 \%$ de suas receitas provenientes das parcelas da participação no resultado ou da compensação financeira pela exploração de petróleo e gás natural (royalties e participações especiais), além de 50\% dos recursos do Fundo Social até que sejam cumpridas as metas estabelecidas no PNE.

Dois aspectos da Lei $\mathrm{n}^{\circ}$ 12.858, de 9 de setembro de 2013, podem ser considerados importantes na perspectiva de ampliar os investimentos em Educação Básica: o primeiro diz respeito à determinação da exclusividade de tais recursos para a educação pública e a priorização da Educação Básica; e o segundo se refere à determinação, no Art. $4^{\circ}$, da aplicação dos recursos em acréscimo ao mínimo obrigatório, ou seja, os governos, não deverão contar tais recursos para contabilizar o percentual mínimo da receita de impostos determinados pela CF/1988.

Essa nova fonte de recursos era esperada como propulsora da meta de investimento de 10\% do PIB em educação. Porém, cabe observar que os estudos realizados ainda em seu processo de tramitação já apontavam sua insuficiência. A Nota Técnica no 14/2013 (TANNO, 2013), produzida pela Consultoria de Orçamento e Fiscalização Financeira da Câmara dos Deputados, em agosto de 2013, já na etapa final do processo de aprovação da Lei n $12.858 / 2013$, apresentou uma projeção do montante dos novos recursos e de seu impacto para o alcance da meta de 10\% do PIB. Os elaboradores fizeram três projeções com base nos três diferentes projetos que tramitaram nas duas casas legislativas. Considerando a projeção feita com base no Parecer ao substitutivo do Senado Federal, aprovado pelo Plenário da Câmara dos Deputados, os novos recursos representariam, nos próximos dez anos (2013-2022), montante estimado de $\mathrm{R} \$ 218$ bilhões destinados à área de educação. Porém, segundo o estudo da referida Nota Técnica, mantendose a taxa otimista de crescimento do investimento público em educação de $6,0 \%$ ao ano e projetando-se a mesma taxa para os próximos 12 anos (2012 a 2023), os investimentos totais em educação atingiriam apenas 7,9\% do PIB em 2023. Assim, para alcançar a meta de 10\% do PIB em 2023, seria necessário ainda um investimento adicional na ordem 1,59 trilhões no período acumulado de 2013 a 2023; portanto, um montante muito além do projetado para a nova fonte no período de 10 anos. 
Deve-se observar, ainda, que o incremento da receita da educação por meio da nova fonte será mais significativa para os estados e municípios produtores ${ }^{3}$ afetados pela exploração de petróleo e gás. Assim, o benefício para os demais municípios seria advindo dos recursos dos royalties e da participação especial dos órgãos da administração direta da União e dos 50\% do Fundo Social.

No entanto, a nova fonte tem sido afetada amplamente pela crise política e econômica envolvendo a Petrobrás, bem como pela disputa entre o governo federal e o governo do estado do Rio de Janeiro em relação à distribuição dos recursos oriundos dos royalties e participações especiais do petróleo e do gás.

O governo do estado do Rio de Janeiro havia ingressado com Ação Direta de Inconstitucionalidade em 15/03/2013 (ADI no 4917/DF), com pedido de medida cautelar contra as novas regras de distribuição dos royalties e participações especiais devidos pela exploração do petróleo, introduzidas pela Lei Federal no 12.734/2012. O Supremo Tribunal Federal concedeu liminar favorável ao Governo do Rio de Janeiro, o que resultou no restabelecimento da redação original dos dispositivos da Lei no 9.478/1997, que previa a destinação de recursos pela exploração de petróleo a diversos órgãos da União: Ministério da Defesa, Ministério do Meio Ambiente, Ministério da Ciência, Tecnologia e Inovação e Ministério de Minas e Energia. (BRASIL, 2013b).

Assim, a arrecadação tem sido muito aquém das projeções iniciais, conforme mostra a mais recente Nota Técnica n $n^{\circ}$ 7/2015 da Consultoria de Orçamento e Fiscalização Financeira da Câmara dos Deputados (TANNO, 2015), que analisou os efeitos da medida cautelar na ADI no 4917/DF para as receitas decorrentes da exploração de petróleo destinadas à educação ${ }^{4}$.

Tal decisão teve efeito direto sobre as novas receitas previstas para a educação. De acordo com a referida nota técnica, as leis orçamentárias de 2014 e 2015 adotaram a hipótese de queda da liminar e a manutenção do texto promulgado da Lei no $12.734 / 2012$, prevendo para a União a vinculação integral

3 De acordo com a Lei no $9.478 / 97$, que definiu o regime de distribuição das receitas de royalties e participações especiais sob o regime de concessão, quando a parcela representar $5 \%$ do contrato, a parcela dos estados e municípios produtores será, respectivamente, de $70 \%$ e $20 \%$, (quando a extração ocorrer em terra, lagos, rios, ilhas fluviais e lacustres) e de 30\% (quando a extração ocorrer em plataforma continental). Quando a parcela do contrato de concessão exceder 5\%, a parcela dos estados e municípios produtores será, respectivamente, de $52,5 \%$ e $15 \%$ (quando a extração ocorrer em terra, lagos, rios, ilhas fluviais e lacustres) e de $22,5 \%$ (quando a produção for extraída da plataforma continental). O percentual restante é dividido entre os Ministérios da Ciência, Tecnologia e Inovação e da Marinha (cujos percentuais variam entre 25\% e 15\%) e entre os municípios afetados pela exploração (com percentuais entre 10 e 7,5\%), dependendo das situações já elencadas quanto ao local e percentual do contrato. (BRASIL, 1997)

4 A análise da referida Nota Técnica não leva em consideração eventuais frustrações decorrentes da exploração e de outros fatores conjunturais, tais como a redução no ritmo de investimentos no setor e a queda do preço de barril de petróleo; considera apenas as perdas oriundas da liminar concedida pelo Supremo Tribunal Federal ao estado do Rio de Janeiro contra as novas regras de distribuição dos royalties e participações especiais devidos aos entes federados. (TANNO, 2015) 
de recursos oriundos da exploração de petróleo ao Fundo Social, dos quais 50\% foram alocados no Ministério da Educação, em conformidade com o disposto no art. $2^{\circ}$, III, da Lei $n^{\circ} 12.858 / 2013$. No entanto, considerando a medida cautelar concedida pelo STF, a execução orçamentária está condicionada ao marco regulatório anterior (Lei $n^{\circ}$ 9.478/1997), de forma que os recursos deixam de ser destinados à educação e são repassados aos órgãos da União anteriormente beneficiados. Assim, das receitas previstas pela Lei $n^{\circ} 12.858 / 2013$, a Lei Orçamentária de 2015 contemplou apenas a parcela correspondente a 50\% das destinações ao Fundo Social, relativas a contratos celebrados sob o regime de concessão não incluídos no inciso I, ou seja, áreas em plataforma continental cuja declaração de comercialidade ocorreram antes de 3 de dezembro de 2012 e áreas exploradas em terra (TANNO, 2015, p. 3).

De acordo com a Nota Técnica, a Lei Orçamentária de 2014 havia estimado uma arrecadação na ordem de $\mathrm{R} \$ 42,7$ bilhões decorrentes da exploração de petróleo, porém esta foi de apenas $\mathrm{R} \$ 35,3$ bilhões. Para a educação estava prevista uma receita de $\mathrm{R} \$ 6,7$ bilhões, porém apenas $\mathrm{R} \$ 1,5$ bilhão foi efetivamente arrecadado, uma vez que os recursos continuam destinados conforme a Lei $\mathrm{n}^{\circ}$ 9.478/1997. Além da arrecadação do Ministério da Educação, a decisão do STF afetou também as receitas da educação dos estados e municípios que tiveram uma redução de sua participação de $68,6 \%$ para $61,3 \%$.

O quadro a seguir apresenta a situação orçamentária das ações previstas com recursos da nova fonte. 
Quadro 01 - Ações orçamentárias financiadas pela Fonte 108 - Parcela do Fundo Social destinada à educação. Lei Orçamentária Anual para 2014.

\begin{tabular}{|c|c|c|c|c|}
\hline AÇÃO & FONTE & $\begin{array}{l}\text { DOTAÇÃO } \\
\text { INIClAL }\end{array}$ & $\begin{array}{c}\text { CRÉDITOS } \\
\text { ADICIONAIS }\end{array}$ & AUTORIZADO \\
\hline \multirow{2}{*}{$\begin{array}{l}\text { CONCESSÃO DE BOLSA DE } \\
\text { APOIO Á EDUCAÇÃO BASICA }\end{array}$} & EDUCAÇÃO & 1.641.572.223 & -1.024 .491 .500 & 617.080 .723 \\
\hline & OUTRAS & 0 & 1.264 .544 .500 & 1.264 .544 .500 \\
\hline \multirow{2}{*}{$\begin{array}{c}\text { APOIO AO DESENVOLVIMENTO } \\
\text { DA EDUCAÇĀO BASICA }\end{array}$} & EDUCAÇÃO & 0 & 562.631 .761 & 562.631 .761 \\
\hline & OUTRAS & 401.664 .698 & 337.968 .239 & 739.632 .937 \\
\hline \multirow{2}{*}{$\begin{array}{c}\text { COMPLEMENTAÇÃO DA UNIÃO } \\
\text { AO FUNDEB }\end{array}$} & EDUCAÇÃO & 681.005 .191 & -562.631 .761 & 118.373 .429 \\
\hline & OUTRAS & 9.674 .353 .478 & 1.066 .731 .761 & 10.741 .085 .239 \\
\hline \multirow{2}{*}{$\begin{array}{l}\text { IMPLANTAÇÃO DE ESCOLAS } \\
\text { PARAA EDUCAÇÂO INFANTIL }\end{array}$} & EDUCAÇÃO & 3.500 .000 .000 & -2.495 .895 .226 & 1.004.104.774 \\
\hline & OUTRAS & & 2.495 .895 .226 & 2.495 .895 .226 \\
\hline \multirow{2}{*}{$\begin{array}{c}\text { IMPLANTAÇÃO E ADEQUAÇÃO } \\
\text { DE ESTRUTURAS ESPORTIVAS } \\
\text { ESCOLARES }\end{array}$} & EDUCAÇÃO & 798.052 .651 & -61.792 .501 & 736.260 .150 \\
\hline & OUTRAS & 202.547 .349 & 61.792 .501 & 264.339 .850 \\
\hline \multirow{2}{*}{$\begin{array}{l}\text { APOIO À CAPACITACÃ̃O } \\
\text { E FORMACCÃO INICIAL } \\
\text { E CONTINUUADA PARAA } \\
\text { EDUCAÇÂOO BÁSICA }\end{array}$} & EDUCAÇÃO & 95.087 .511 & 0 & 95.087 .511 \\
\hline & OUTRAS & 149.138 .098 & 60.800 .000 & 209.938 .098 \\
\hline \multirow{5}{*}{$\begin{array}{l}\text { APOIO À MANUTENĈ̃̃O DA } \\
\text { EDUCAÇÃO INFANTIL }\end{array}$} & EDUCAÇÃO & 0 & 61.792 .501 & 61.792 .501 \\
\hline & OUTRAS & 142.796 .125 & -59.671 .661 & 83.124 .464 \\
\hline & EDUCAÇÃO & 6.715 .717 .576 & -3.520 .386 .726 & 3.195 .330 .850 \\
\hline & OUTRAS & 10.570 .499 .748 & 5.228 .060 .566 & 15.798 .560 .314 \\
\hline & TOTAL & 17.286 .217 .324 & 1.707 .673 .840 & 18.993.891.164 \\
\hline
\end{tabular}

Fonte: Tanno (2015, p. 9)

O Quadro 1 apresenta os recursos previstos pela LOA de 2014 e o que foi efetivamente arrecadado da fonte da exploração de petróleo para a educação, bem como os recursos adicionais oriundos de outras fontes. A arrecadação negativa da nova fonte levou o governo federal a realizar o cancelamento de $\mathrm{R} \$ 3,5$ bilhões das dotações autorizadas e a compensação por meio do acréscimo de dotações, da ordem de R \$ 5,2 bilhões nessas mesmas ações com a utilização de outras fontes. Para o ano de 2015, a lei orçamentária estimou a arrecadação de royalties e participação especial destinados à educação de 7,0 bilhões. Porém, considerandose o efeito da liminar, a arrecadação provavelmente será de apenas 3,5 bilhões. Além disso, com o agravamento da crise, a possibilidade de compensações ocorridas em 2014 parece menor, comprometendo ainda mais a perspectiva de alcance da meta de investimentos em educação ao patamar de $10 \%$ do PIB, conforme previsto pelo PNE 2014-2022.

Observando-se a receita dos principais mecanismos de financiamento da Educação Básica, constata-se que o alcance do Custo Aluno Qualidade inicial 
está bastante comprometido. A receita do Fundeb vem diminuindo, desde 2011, o ritmo de crescimento em relação aos seus quatro primeiros anos. Em 2010, o aumento real da receita em relação ao ano anterior foi de 14\%. Porém, a partir de então, o aumento de receita veio diminuindo gradativamente e apresentou queda de 1\% de 2013 para 2014 e de $\%$ para 2015, incluindo a complementação da União (valores corrigidos pelo IPCA de julho de 2015). Esta, por sua vez, vem sendo mantida no mínimo estabelecido pela Lei, ou seja, o equivalente a $10 \%$ do total dos fundos ${ }^{5}$. Além disso, apresentaram queda drástica as transferências dos Programas de assistência legal e voluntária da União, que vinham mantendo considerável ritmo de crescimento desde 2004 até o ano de 2010. As transferências dos programas de assistência legal apresentaram queda de 44\% de 2010 para 2014 e as dos programas de assistência voluntária caíram 22\% no mesmo período. ${ }^{6}$ Observe-se que as transferências desses programas apresentam queda significativa a partir de 2010, quando a complementação da União, por obrigação legal, atinge os $10 \%$ do total da composição dos fundos estaduais.

Tomando-se como referência os recursos do principal arranjo de financiamento da Educação Básica, no ano de 2014, pode-se observar que os valores praticados estão muito distantes do alcance do CAQi e tal perspectiva depende amplamente de maior participação da União. Com base no estudo de Pinto (2015), o gráfico a seguir apresenta o valor médio aluno no âmbito de cada estado no ano de 2014, com e sem a complementação da União.

Tomando-se como referência o CAQi, as perspectivas de equidade entre os entes federados tornam-se mais complexas. Em valores atualizados para 2014, o valor médio aluno do CAQi seria de $\mathrm{R} \$ 5.445,80$, o que significa que, nem mesmo o maior valor médio do país, o de Roraima, aproxima-se de um padrão mínimo de qualidade.

\footnotetext{
5 Dados oriundos das planilhas divulgadas pelo FNDE, incluindo ajustes feitos no ano posterior.

6 Dados oriundos do Portal da Transparência

$7 \quad \mathrm{O}$ valor médio aluno corresponde à razão entre valor total do Fundeb recebido pelos estados e a matrícula em Educação Básica pública (rede estadual + rede municipal) no ano de 2014.
} 


\section{Gráfico 1 - Valor médio do Fundeb por aluno com e sem a complementação da União - Brasil, 2014}

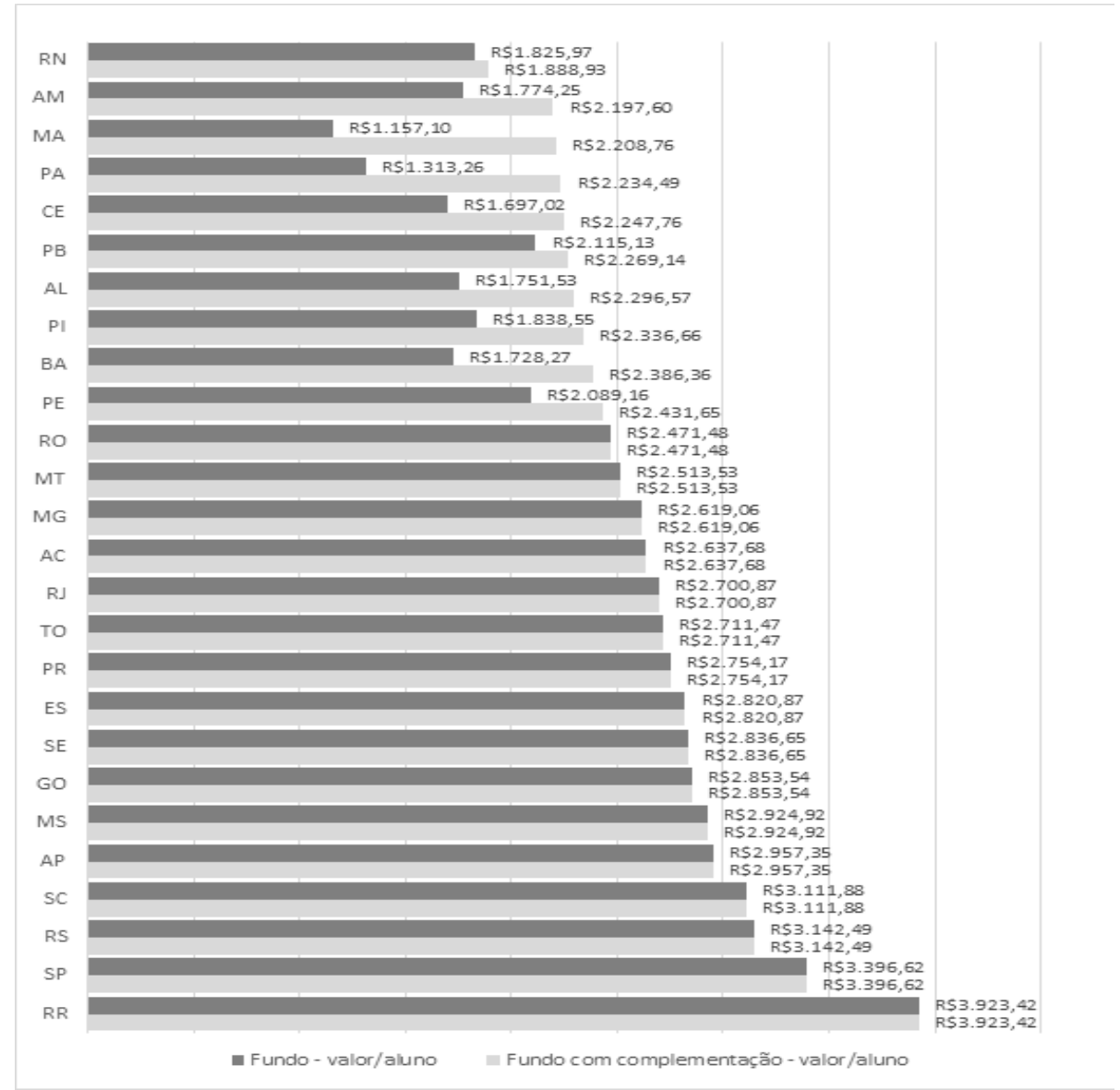

Fonte: Elaboração da autora com base em dados do FNDE/Fundeb (2014) e INEP (Censo Escolar, 2014).

Observa-se que a complementação da União altera significativamente o valor médio aluno, disponível somente com os recursos do fundo estadual, em especial nos estados do Maranhão e do Pará. Comparando-se o maior valor médio aluno do Maranhão, mesmo com a complementação da União, com o de Roraima, maior valor médio aluno, tem-se uma variação de 75,58\%. Portanto, um aporte maior de recursos da União é essencial para se avançar no alcance do CAQi. 


\section{CONSIDERAÇÕES FINAIS}

Desde a aprovação da Constituição de 1988 e, principalmente, após a promulgação da Lei $n^{\circ} 9.394 / 1996$, a LDB, diversos arranjos foram sendo desenvolvidos na perspectiva de garantir melhor alinhamento entre o sistema de divisão de responsabilidades e o sistema de divisão dos recursos financeiros, com vistas a garantir o cumprimento do preceito do direito de todos à educação com qualidade.

Observa-se, portanto, que novas perspectivas se apresentaram no campo do financiamento com vistas ao aumento do investimento na Educação Básica. Estas apontam para um redimensionamento da relação entre as dimensões da quantidade e da qualidade, na medida em que a quantidade de insumos e, consequentemente, de recursos constitui uma importante dimensão da qualidade, em especial quando ambas as dimensões são concebidas na perspectiva da garantia de equidade na oferta educacional. Dessa forma, equidade e qualidade têm sido princípios propulsores de iniciativas na direção de mais recursos para a Educação Básica.

As tensões entre melhoria da qualidade e a expansão dos recursos financeiros para a oferta e a manutenção da Educação Básica têm gerado novas proposições e novos arranjos político-administrativos que manifestam também forças em disputa, seja entre os governos seja entre estes e a sociedade civil. As novas proposições envolvem também tensões no âmbito do legislativo, que se expressam nos diversos projetos que tramitam na Câmara dos Deputados visando à regulamentação do Custo Aluno Qualidade, do regime de colaboração, do Sistema Nacional de Educação e da proposta de uma lei de responsabilidade educacional.

O Fundeb constituiu um passo adiante na perspectiva de equalização das condições de oferta e manutenção da educação. Entretanto, em um contexto de grandes assimetrias espalhadas no vasto território brasileiro, que impactam tanto a receita de impostos dos diferentes entes quanto as condições de oferta e manutenção da educação, os recursos e mecanismos de redistribuição do novo fundo ainda se mostram insuficientes para a garantia do direito de todos à educação e, portanto, deixam de atender aos princípios constitucionais de um padrão mínimo de qualidade e de equidade na oferta da educação.

Os debates ocorridos no âmbito da CONAE e no processo de aprovação do novo PNE acerca do regime de colaboração e de mecanismos na perspectiva da qualidade e da equidade resultaram em avanços significativos em termos de metas, a exemplo da meta 20, que visa a ampliar o investimento público em educação a um patamar de 10\% do PIB ao final do decênio, e suas estratégias em termos 
de implementação do CAQ e da regulamentação do regime de colaboração entre a União, os estados e os municípios. Esse processo ocorreu, porém, em meio a muitas tensões entre as organizações da sociedade civil e o governo federal, tanto no âmbito do legislativo quanto do executivo, envolvendo, em especial, a tensão entre os conceitos de gasto versus investimento público em educação e a tensão entre investimento público em educação e investimento em educação pública.

O cumprimento das metas previstas no PNE 2014-2024 incide diretamente sobre um maior aporte de recursos da União, o que está assinalado na estratégia 20.10 e tem tensionados os debates e iniciativas no campo do financiamento. Observa-se, porém, que o investimento da União em Educação Básica pública tem-se limitado ao cumprimento do mínimo estabelecido legalmente no âmbito do Fundeb e, ainda assim, às custas de recursos de outras ações de sua assistência financeira, o que torna mais distante o alcance do CAQi no financiamento da Educação Básica.

\section{REFERÊNCIAS}

ARAUjO, Gilda Cardoso; OLIVEIRA, Romualdo Portela de. Qualidade do ensino: uma nova dimensão da luta pelo direito à educação. Revista Brasileira de Educação. Rio de Janeiro, n. 28, p. 5-23, jan / fev / mar /abr. 2005.

ARAÚJO, Raimundo Luiz Silva. Limites e possibilidades da redução das desigualdades territoriais por meio do financiamento da educação básica. 2013. 416 f. Tese (Doutorado em Educação) - Programa de Pós-graduação em Educação, Universidade de São Paulo, São Paulo, 2013.

Nota técnica $\mathrm{n}^{\circ} \mathbf{0 1 0 / 2 0 1 4}$ : indicadores financeiros educacionais. Investimento Público em educação. Brasília, DF, INEP, 2014.

Lei $\mathbf{n}^{\mathbf{0}} \mathbf{1 2 . 8 5 8}$, de 9 de setembro de 2013. Dispõe sobre a destinação para as áreas de educação e saúde de parcela da participação no resultado ou da compensação financeira pela exploração de petróleo e gás natural, com a finalidade de cumprimento da meta prevista no inciso VI do caput do art. 214 e no art. 196 da Constituição Federal. Brasília, DF, 9 set. 2013a. Disponível em: http://www.planalto.gov.br/ccivil_03/_Ato2011-2014/2013/Lei/L12858.htm. Acesso em: 7 jul. 2015. 
Supremo Tribunal Federal. ADI 4917 MC / DF. Medida Cautelar na Ação Direta de Inconstitucionalidade. Relator: Min. Cármen Lúcia. Brasília, 18 de março de 2013b. Disponível em: <http://www.stf.jus.br/arquivo/cms/ noticianoticiastf/anexo/ adi4917liminar.pdf >. Acesso em: 12 jun. 2015.

. Conferência Nacional de Educação (CONAE) 2010: Construindo o Sistema Nacional Articulado de Educação: Plano Nacional de Educação, diretrizes e estratégias; Documento Final. Brasília, DF: MEC, 2010a. Disponível em: $<$ http://conae.mec.gov.br/ images/.stories/pdf pdf/documetos/ documento_ final.pdf $>$. Acesso em: 16 maio. 2012.

. Parecer CNE/CEB n ${ }^{\mathbf{0}}$ 08/2010. Estabelece normas para aplicação do inciso IX do artigo $4^{\circ}$ da Lei no 9.394/96 (LDB), que trata dos padrões mínimos de qualidade de ensino para a Educação Básica pública. Brasília, DF, 2010 b.

Projeto de Lei 8.035, de 20 de dezembro de 2010. Aprova o Plano Nacional de Educação para o decênio 2011-2020 e dá outras providências. Brasília, DF: Câmara dos Deputado, 20 dez. 2010c. Disponível em: http://www.camara. gov.br/sileg/integras/ 831421.pdf. Acesso em: 10 set. 2013.

. Notas técnicas do MEC ao PNE 2011-2020. Brasília: Ministério da Educação. 2010d. Disponível em: <http://fne.mec.gov.br/images/pdf/notas_ tecnicas_pne_2011_2020.pdf>. Acesso em: 20 mai.2013.

Lei $\mathrm{n}^{\mathrm{o}} 11.494$ de 20 de junho de 2007. Regulamenta o Fundo de Manutenção e Desenvolvimento da Educação Básica e de Valorização dos Profissionais da Educação - FUNDEB, de que trata o art. 60 do Ato das Disposições Constitucionais Transitórias; altera a Lei no 10.195, de 14 de fevereiro de 2001; e dá outras providências. Brasília, DF, 20 jun. 2007c. Disponível em: <http://www.planalto.gov.br/ccivil_03/_ato2007-2010/2007/lei/111494.htm>. Acesso em: 19 mai. 2014.

. Lei $\mathbf{n}^{\circ} \mathbf{9 . 4 7 8}$, de 6 de agosto de 1997. Dispõe sobre a política energética nacional, as atividades relativas ao monopólio do petróleo, institui o Conselho Nacional de Política Energética e a Agência Nacional do Petróleo. Brasília, DF, 1997. Disponível em: < http://www.planalto.gov.br/ccivil_03/LEIS/L9478. htm>. Acesso em: 12 jun. 2015. 
Lei $\mathbf{n}^{\circ}$ 9.394/96 de 20 de dezembro de 1996. Estabelece as Diretrizes e Bases da Educação Nacional. Brasília, DF, 20 dez, 1996a. Disponível em: < http:/ / www.planalto.gov.br/ccivil_03/ leis/19394.htm>. Acesso em: 05 mai. 2013.

Lei $\mathrm{n}^{\circ} \mathbf{9 . 4 2 4}$, de 24 de dezembro de 1996. Dispõe sobre o Fundo de Manutenção e Desenvolvimento do Ensino Fundamental e de Valorização do Magistério, na forma prevista no art. 60, $\int 7^{\circ}$, do Ato das Disposições Constitucionais Transitórias, e dá outras providências. Brasília, DF, 24 dez, 1996b. Disponível em: <http://www.planalto.gov.br/ccivil_03/leis/19424.htm>. Acesso em: 11 jun. 2013.

Constituição da República Federativa de 1988. Brasília: Senado FederaL, 1988. Disponível em: < http://www.planalto.gov.br/ccivil_03/ Constituicao/ Constituicao.htm>. Acesso em: 05 abr. 2012.

CARREIRA, Denise; PINTO Marcelino Rezende. Custo aluno-qualidade inicial: rumo à educação pública de qualidade no Brasil. São Paulo: Global/ Campanha Nacional pelo Direito à Educação, 2007.

PINTO, José Marcelino Rezende. O FUNDEB na perspectiva do custo aluno qualidade. Em Aberto. Brasília, v.28, n.93, p. 101-118, jan./jun. 2015.

TANNO, Claudio Riyudi et all. Nota técnica $\mathbf{n}^{\mathbf{o}}$ 14/ 2013: Destinação para as áreas de educação e saúde de parcela da participação no resultado ou da compensação financeira pela exploração de petróleo e gás natural. Brasília: Câmara dos deputados / consultoria de orçamento e fiscalização financeira. Disponível em: < http://www2. camara.leg.br/atividade-egislativa/orcamentobrasil/ estudos/2013/NT14.pdf>. Acesso em 06 maio. 2015.

TANNO, Claudio Riyudi. Nota técnica $\mathbf{n}^{\mathbf{0}}$ 7/ 2015: efeitos da medida cautelar na ADI n ${ }^{\circ} 4917 / d f$ e a frustração de receitas decorrentes da exploração de petróleo destinadas à educação. Brasillia: Câmara dos deputados / consultoria de orçamento e fiscalizacao financeira. Disponível em: <http://www2.camara. leg.br/atividade-legislativa/ orcamentobrasil/estudos/2015/NT07_ 2015.pdf>. Acesso em 12 jun. 2015. 
CACILDA RODRIGUES CAVALCANTI é doutora em Educação pela UFMG, professora do Departamento de Educação II da Universidade Federal do Maranhão (UFMA), com atuação profissional e acadêmica no campo de políticas públicas de educação, em especial, no campo da gestão e do financiamento da educação básica. E-mail: cavalcanticacilda@gmail.com

Recebido em abril de 2016

Aprovado em junbo de 2016 